Consumo. Envelhecimento. Imaginário. Corpo. 


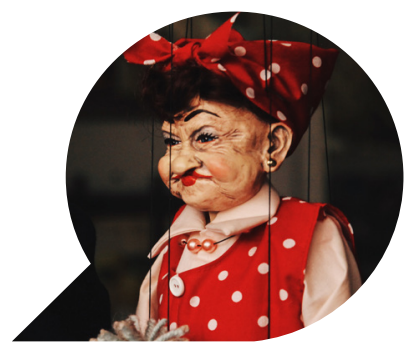

\title{
Envelhecimento intolerável: consumo midiático e o imaginário do corpo
}

\author{
Intolerable Aging: \\ Media Consumption and the Imaginary of the Body \\ Envejecimiento Intolerable: \\ Consumo Mediático y el Imaginario del Cuerpo
}

\section{DENISE REGINA STACHESKI*}

Resumo: Este artigo se propõe a estudar narrativas midiáticas que contemplem representações do envelhecimento intolerável. O texto perpassa pela discussão da responsabilidade dos sujeitos frente à velhice e pelos códigos do saber viver para a manutenção do corpo jovem. Como abordagem metodológica foi realizada uma análise de conteúdo, a partir de conceitos de Le Breton (2011) sobre o imaginário do corpo, emunidades comunicativas publicadas no jornal Gazeta do Povo (online), Paraná, entre janeiro a julho de 2017. Verifica-se, entre os resultados, a enaltação midiática de valores simbólicos como juventude, vitalidade e corpo físicoperfeito. Paradigmas do imaginário do corpo que podem dificultar as vivências no processo do envelhecimento.

Palavras-chave: Consumo midiático; Envelhecimento; Gazeta do Povo; Imaginário do corpo.

\footnotetext{
* Professora da Universidade Federal do Paraná, Universidade Positivo e Universidade Tuiuti do Paraná. Possuidoutorado e mestrado em Comunicação e Linguagens pela Universidade Tuiuti do Paraná e graduação em Comunicação Social -Relações Públicas pela Universidade Federal do Paraná. E-mail: 
Abstract: This article proposes to study media narratives that contemplate representations of intolerable aging. The text goes through the discussion of the responsibility of the subjects in the face of old age and the codes of living knowledge for the maintenance of the young body. As a methodological approach, a content analysis was carried out, based on Le Breton (2011) concepts about the body imagery, in communicative units published in the newspaper Gazeta do Povo (online), Paraná, between January and July 2017. Among the results, the mediatic ennui of symbolic values such as youth, vitality and perfect physical body. Paradigms of the body's imagery that can make life difficult in the aging process.

Keywords: Media Consumption; Aging; Gazeta do Povo; Body imagery.

Resumen: Este artículo se propone a estudiar narrativas mediáticas que contemplan representaciones del envejecimiento intolerable. El texto pasa por la discusión de la responsabilidad de los sujetos frente a la vejez y por los códigos del saber vivir para el mantenimiento del cuerpo joven. Como enfoque metodológico se realizó un análisis de contenido, a partir de conceptos de Le Breton (2011) sobre el imaginario del cuerpo, en unidades comunicativas publicadas en el diario Gazeta del Pueblo (Online), Paraná, entre enero y julio de 2017. Entre los resultados, la enaltación mediática de valores simbólicos como juventud, vitalidad y cuerpo físico perfecto. Paradigmas del imaginario del cuerpo que pueden dificultar las vivencias en el proceso del envejecimiento.

Palabras clave: Consumo mediático; Envejecimiento; Gazeta do Povo; Imaginario del cuerpo. 


\section{Introdução}

Em 2060, o número de idosos, no Brasil, com 80 anos ou mais, pode ultrapassar os 19 milhões (IBGE, 2016). Estatística que demonstra o rápido envelhecimento populacional brasileiro que demanda refletir, estudar e planejar novas estruturas, físicas e emocionais, no cotidiano das cidades. Questões que precisam ser (re) significadas, nas interações cotidianas, como as representações sociais e o imaginário do corpo no processo da velhice. É urgente que o envelhecimento possa se tornar um processo natural e saudável nas coletividades modernas.

Há um longo caminho a ser percorrido, pois diversos estigmas negativos são reforçados diariamente nas narrativas midiáticas (STACHESKI, 2014). Entre eles, a visão em que envelhecer é intolerável. Como afirma Le Breton (2011, p. 224), "a pessoa idosa avança em direção a morte e nela encarnaos dois inomináveis da modernidade: o envelhecimento e a morte". Envelhecer se torna um peso, uma opção não aceitável para a maioria dos ocidentais. Assim, o sujeito combate o envelhecimento por meio de códigos do saber viver - isto é, regras e normativas a serem seguidas, fortalecidas nas narrativas midiáticas.

Um corpo que não pode envelhecer, que se constitui em uma forma de consumo cultural - buscar atender necessidades mercadológicas da cultura de consumo (LE BRETON, 2011). Um corpo que permite ser o instrumento pelo qual o sujeito transmite um estilo por ele construído, mediado, principalmente, pela mídia (CASTRO, 2004). Um imaginário do corpo com etiquetas corporais precisas que se estabelecem e se socializam em relação com o corpo sob a forma de recalque (LE BRETON, 2011).

A partir dessa contextualização, este artigo se propõe a estudar narrativas midiáticas que contemplem representações do envelhecimento intolerável. Parte-se da premissa que a mídia é uma multiplicadora dessa visão social sobre o envelhecimento (STACHESKI, 2014), ao impor aos sujeitos a responsabilidade sobre sua velhice. Como abordagem metodológica foi realizada uma análise de conteúdo, a partir de conceitos de Le Breton (2011) sobre o imaginário do corpo, em unidades comunicativas publicadas no jornal Gazeta do Povo (online), Paraná, entre janeiro a julho de 2017. 


\section{O Envelhecimento Intolerável e Responsabilidade do Sujeitofrente à Velhice}

O processo de perdas biológicas, culturais e sociais, até então significantes do processo de envelhecer, é substituído, na modernidade, pela busca de prazer e satisfação pessoal, como afirma Debert (1999). A autora denuncia que essa significação traz uma nova abordagem do envelhecimento, com o objetivo de "reprivatizar a velhice". Para Debert (1999), o discurso implementa a responsabilidade dos idosos frente à própria velhice. No entanto, o envelhecimento mantém seu estigma negativo, como o descuido pessoal do sujeito, a sua falta de envolvimento em atividades motivadoras, as erradas formas de consumo e aos estilos de vida inadequados (STACHESKI, 2014).

O idoso é conduzido, a partir deste imaginário, para fora do campo simbólico da modernidade - que fortalece significações de juventude, de sedução, de vitalidade, de trabalho. Envelhecer é tido como um "lembrete da precariedade e da fragilidade da condição humana" (LE BRETON, 2001, p. 224). A velhice, assim, não é percebida como algo inerente ao passar dos anos, mas como fonte de transgressões das pessoas e, por isso, não merece piedade social.

O status atual das pessoas idosas, a denegação que marca a relação por cada um com seu próprio envelhecimento, a denegação também da morte; eis os sinais que mostram as resistências do homem ocidental em aceitar os dados da condição que faz dele, antes de tudo, um ser de carne (LE BRETON, 2011, p. 237).

Nas últimas décadas, espaços foram e são crescentemente abertos para que experiências diversas do envelhecimento e da aposentadoria possam ser vivenciadas de maneira mais gratificante pelos idosos (DEBERT, 1999; STACHESKI, 2014). Mas o compromisso da coletividade para com o envelhecer positivado desemboca em práticas que, ao oportunizar constantes atitudes e ações para um imaginário do corpo renovado, de identidades e de autoimagens, encobrem, frequentemente, problemas próprios da idade mais avançada, uma não aceitação da velhice (STACHESKI, 2014). Como afirma LE BRETON (2011, p. 237): "o envelhecimento em termos ocidentais, marca a redução progressiva do corpo, uma espécie de escravização a uma dualidade que opõe o sujeito ao seu corpo e o torna dependente deste último". 
Dentro desta representação, um imaginário do envelhecimento intolerável, os sujeitos envelhecem porque não cuidaram de seus corpos corretamente. Umavalorização da saúde perfeita que vem com uma roupagem "sanitária" que promete, pelos progressos das ciências da saúde, um mundo sem males e sem dor (JUNGES, 2004). Sujeitos que devem controlar seu corpo e se responsabilizar por suas decadências físicas retirando dos âmbitos sociais a obrigação de lidar com a população idosa, reprivatizando a velhice, uma governança de si mesmo. Juventude não mais em relação com uma faixa etária específica, mas uma relação com o imaginário do corpo jovem, perfeito, com comportamentos que devem ser seguidos (e conseguidos) pelos sujeitos por toda a vida.

Códigos do saber viver, apelos para não envelhecer, que são multiplicadosnas interações diárias e fortalecidos nas narrativas midiáticas. Basta mapear a quantidade de livros, reportagens, publicidades e propagandas que abordam os perfeitos estilos de vida e garantem ser possível intervir no processo da velhice. Narrativas que valorizam simbolicamente a responsabilidade do sujeito em relação à velhice, à privatização do envelhecimento (DEBERT, 1999). Para Le Breton (2011), o corpo do sujeito tornou-se um conjunto de valores eróticos que invadem a publicidade, a mídia em geral. Narrativas que constroem representações sociais, refletem e fortalecem, juntamente com diversos atores sociais, um culto ao não envelhecimento. Uma busca pelo paradigma do corpo confiável, um corpo ajustado, supervisionado e pleno de vitalidade (LE BRETON, 2011).

\section{Idosos, Mídia e Representações Sociais}

As representações sociais do envelhecimento estão nas práticas e nos processos de comunicação, nas narrativas midiáticas, na coletividade onde os sujeitos estão inseridos. Como argumenta Marques (2011, p. 38), "quando classificamos as pessoas em determinadas categorias, não o fazemos de um modo isolado, mas somos influenciados pelo modo como as sociedades em que vivemos concebem estas diferentes categorias e pelas representações que lhes estão normalmente associadas". Assim, o idoso a partir de seu lugar social se apresenta e se constitui de acordo com o que concebe de seu mundo. Le Breton (2001, p.235) corrobora com essa ideia e afirma: "a imagem do corpo não é um dado objetivo, não é um fato, é um valor que resulta essencialmente da influência do ambiente e da história pessoal do sujeito". Matos (2011, p. 43) também reforça: "é justamente no processo de socialização que o idoso encontrará sua identidade, como sujeito e agente social”. 
O processo de socialização e as interações cotidianas, bem como a construção de valores simbólicos, estão fortemente vinculados aoconsumo midiático. A mídia, segundo Silverstone (2002), tem o poder de abrir e fechar portas, de controlar direitos de passagem, de permitir o acesso e a produção de significados. Silverstone (2002) também afirma que é impossível, atualmente, escapar da presença e da representação da midiática que oferece e produz significados que inundam o dia-adia das coletividades.

Narrativas que mediam, que pressupõem vínculos e implicamem um constante processo de produção de significados e ressignificações. A mídiarepresenta, portanto, um forte dispositivo de produção de identidades, de representações e contemplações dos sujeitos - inclusive sobre o imaginário do corpo no envelhecimento. Como afirma Silverstone (2002, p. 13), é preciso estudar a mídia, "como algo que contribui para a nossa variável capacidade de compreender o mundo, de produzir e partilhar significados".

Pelas interações midiáticas, portanto, o imaginário do corpo e do envelhecimento são significados. Isto é, a voz que o sujeito constrói, os valores simbólicos em relação à velhice, é uma adaptação às possíveis expressões e narrativas midiáticas existentes no social. "É o outro, sobretudo, que espelha sob uma forma depreciativa a inscrição da senescência”, como afirma Le Breton (2011, p. 235). Uma abordagem diálogica entre o consumo midiático e os valores simbólicos do processo de envelhecimento. Um processo contínuo e incessante, segundo Silverstone (2002, p.30), “o social está sendo constantemente reproduzido". Com isso, analisar narrativas midiáticas que possam significar contextos do envelhecimento intolerável, bem como da responsabilidade do sujeito frente à velhice, se torna essencial para verificar valores simbólicos, imaginários do corpo e representações sociais postos em nossa sociedade.

\section{Abordagem Metodológica}

Como abordagem metodológica, deste estudo, foi realizada uma análise de conteúdo em uma amostra não probabilística de dezunidades comunicativas publicadas no site do jornal Gazeta do Povo (2017), do Estado do Paraná, entre janeiro a julho de 2017, que abordaram questões sobre o imaginário do corpo no envelhecimento. 
O processo para a seleção da amostra contou com as seguintes fases: a) levantamento de unidades comunicativas publicadas pela Gazeta do Povo por meio do sistema de busca ofertado pelo site do jornal (ao digitar o termo envelhecimento foram totalizadas1320 unidades comunicativas entre notícias, artigos, blogs, informações); b) categorização de análise e unidades de contexto. A categorização da análise de conteúdo e a determinação das variáveis para a seleção das unidades analisadas foram embasadas pela proposta já desenvolvida por STACHESKI (2014). Nessa linha, portanto, para a seleção buscou-se identificar unidades comunicativas que contivessem pelo menos uma das seguintes variáveis (unidades de contexto) nas publicações levantadas: a) alimentação saudável para combater o envelhecimento; b) exercícios físicos e mentais para combater o envelhecimento e c) busca pelo modelo do corpo jovem.

As publicações analisadas, títulos e datas, constam na tabela 01, a seguir apresentada.

Tabela 01: Relação da amostra analisada

\begin{tabular}{|c|c|c|c|}
\hline REF. & TÍTULO & AUTORIA & DATA \\
\hline 1 & $\begin{array}{l}\text { Um terço dos casos de demência pode ser evitada com } 9 \text { mudanças de } \\
\text { hábitos. Aumento do contato social e exercícios físicos para pessoas } \\
\text { com doenças degenerativas são medidas que podem ajudar na } \\
\text { prevenção da demência. }\end{array}$ & $\begin{array}{l}\text { Agência } \\
\text { do Estado } \\
\text { (2017) }\end{array}$ & $20 / 07 / 2017$ \\
\hline 2 & $\begin{array}{l}\text { Aprender a dançar o minueto ou o fandango protege nosso cérebro do } \\
\text { envelhecimento? Dança de salão, que exige o aprendizado de } \\
\text { coreografias, afeta o cérebro de forma diferente na comparação com } \\
\text { outros exercícios, segundo pesquisa. }\end{array}$ & $\begin{array}{l}\text { The New } \\
\text { York } \\
\text { Times } \\
(2017)\end{array}$ & $09 / 04 / 2017$ \\
\hline 3 & 10 motivos para praticar Pilates na melhor idade. & $\begin{array}{l}\text { Lemos } \\
(2017)\end{array}$ & $08 / 04 / 2017$ \\
\hline 4 & $\begin{array}{l}\text { Adultos e idosos não devem parar de tomar leite, diz Dráuzio Varella. } \\
\text { O médico oncologista esteve em Curitiba fala da importância em } \\
\text { tomar leite, mesmo na fase adulta. Veja a entrevista exclusiva!. }\end{array}$ & $\begin{array}{l}\text { Milléo } \\
(2017)\end{array}$ & $08 / 04 / 2017$ \\
\hline 5 & $\begin{array}{l}\text { "Botox pode, sim, prevenir rugas", afirmam especialistas } \\
\text { No lugar de apenas disfarçar as linhas de expressão, o botox é capaz de } \\
\text { prevenir o surgimento das rugas ao longo do tempo. }\end{array}$ & $\begin{array}{c}\text { Mori } \\
(2017)\end{array}$ & $26 / 03 / 2017$ \\
\hline 6 & Diário de uma triatleta - Quando o esporte desafia a beleza! & $\begin{array}{l}\text { Duarte } \\
(2017)\end{array}$ & $22 / 02 / 2017$ \\
\hline 7 & $\begin{array}{l}\text { Crise freia investimento em inovação no Brasil. E isso pode custar } \\
\text { caro no futuro. Cada vez mais, país corre o risco de envelhecer antes } \\
\text { de se tornar uma nação desenvolvida. }\end{array}$ & $\begin{array}{l}\text { Junges } \\
(2017)\end{array}$ & $03 / 02 / 2017$ \\
\hline 8 & $\begin{array}{c}\text { Tecnologia pode tornar imortal quem hoje tem menos de } 40 \text { anos, } \\
\text { defende pesquisador. }\end{array}$ & $\begin{array}{l}\text { Estadão } \\
\text { Conteúdo } \\
\text { (2017) }\end{array}$ & $02 / 02 / 2017$ \\
\hline 9 & $\begin{array}{l}\text { Maratonista de } 85 \text { anos é tão rápido que espanta até cientistas } \\
\text { Britânico Ed Whitlock recentemente completou maratona em menos } \\
\text { de } 4 \text { horas, algo nunca registrado por alguém na sua faixa etária. }\end{array}$ & $\begin{array}{l}\text { The New } \\
\text { York } \\
\text { Times } \\
(2017)\end{array}$ & $20 / 01 / 2017$ \\
\hline 10 & $\begin{array}{l}\text { Ácidos para a pele podem ser usados no verão. Veja quais!Algumas } \\
\text { formulações podem ser usadas no calor, desde que com o uso de } \\
\text { protetor solar, e os resultados complementam os efeitos do tratamento } \\
\text { no inverno }\end{array}$ & $\begin{array}{c}\text { Da } \\
\text { Redação } \\
(2017)\end{array}$ & $18 / 01 / 2017$ \\
\hline
\end{tabular}

Fonte: Gazeta do Povo, 2017. 
A seguir, resumos de descrição e fragmentos daanálise realizada nas dezunidades selecionadas.

Na unidade comunicativa 1, com o título, "Um terço dos casos de demência pode ser evitada com 9 mudanças de hábitos", da Agência do Estado, publicada na editoria de Sáude e Bem Estar do Jornal Gazeta do Povo, na data de 20/07/2017, se tem a informação de que o aumento do contato social e exercícios físicos para pessoas com doenças degenerativas são medidas que podem ajudar na prevenção da demência. Seguetrecho do conteúdo:

Controlar fatores do estilo de vida, como a perda de audição, tabagismo, hipertensão e depressão pode evitar um terço dos casos de demência no mundo, de acordo com um novo estudo publicado na revista científica Lancet. [...]. Além de revelar que um a cada três casos de demência é passível de prevenção, o relatório destaca também os efeitos benéficos de intervenções não farmacológicas como contato social e exercícios para pessoas com a doença degenerativa (AGÊNCIA DO ESTADO, 2017).

O estudo retratado no texto traz que um a cada três casos de demência é passível de prevenção - portanto, cabe ao sujeito verificar quais hábitos e condições necessárias para que consiga evitar a demência (exercícios e contato social). A responsabilidade do indivíduo sobre seu corpo e suas capacidades mentais. Um novo imaginário do corpo, um novo "poder" do sujeito, que conquista práticas e discursos da mídia - um lugar de combate frente à realidade do seu corpo, graças às suas ações e esforços (como maratonas, exercícios diários) - ou frente habilidade específicas que devem ser estimuladas, como a dança, por exemplo (LE BRETON, 2011).

$\mathrm{Na}$ unidade comunicativa 2, com o título "Aprender a dançar o minueto ou o fandango protege nosso cérebro do envelhecimento?", do The New York Times, publicada na Gazetado Povo, em 09 de abril de 2017, afirma que a dança de salão, que exige o aprendizado de coreografias, afeta o cérebro de forma diferente na comparação com outros exercícios. Novamente o discurso da busca e prática pela habilidade como combate ao envelhecimento. Vieira e Nascentes (2002, p. 04) explicam: "desde a idade média os alquimistas tentam descobrir o elixir da longa vida e, se ainda não foi possível, podemos crer que realmente não é tarefa das mais fáceis alcançar 60 anos mantendo as 
mesmas capacidades físicas dos 20". Assim, os sujeitos devem adquirir hábitos que proporcionem o antienvelhecimento, de acordo com esse imaginário (STACHESKI, 2014).

Na unidade comunicativa 3, com o título,"10 motivos para praticar pilates na melhor idade", publicada em 08/04/2017, no blog, Palpite de Alice, de Lemos (2017), há um incentivo para a prática de pilates por meio dos seguintes benefícios: aumento da força muscular; melhora da mobilidade; melhora do equilíbrio e coordenação motora; melhora a saúde das articulações; diminui dores musculares e articulares; previne incontinência urinária; melhora a capacidade respiratória; melhora dos movimentos para as atividades da vida diária; melhora da autoestima e promove a socialização. A partir desses efeitos, como afirma a autora do texto: "todos nós estamos constantemente dentro desse processo de envelhecimento. Então que isso aconteça de maneira feliz e saudável e, o pilates pode ser o caminho para que seja assim. Porque envelhecer eu vou, com qualidade eu posso!"

Na unidade comunicativa4, com o título,"Adultos e idosos não devem parar de tomar leite", de Milléo (2017), publicada na Gazeta do Povo, no dia 08/04/2017, na editoria de Sáude, há a indicação de ingestão de leite entre crianças, adultos e idosos. Segundo o médico entrevistado, Dráuzio Varela, "tomar leite não é uma necessidade que se encerra na infância. Adultos e idosos precisam de tanto leite quanto as crianças, pois o envelhecimento reduz a produção de tecido ósseo, que necessita do cálcio presente no alimento e nos derivados”. Assim, mais uma regra é apresentada ao sujeito com o objetivo de prevenir as doenças que podem chegar no processo da vida. A partir dos diversos códigos do bem viver, se tem, também, o culto ao nãoenvelhecimento. Um processo que deve ser, sob essa visão, mensurado e calculado pelo sujeito.

A unidade comunicativa 5, com o titulo, "Botox pode, sim, prevenir rugas", afirmam especialistas", publicada na Gazeta do Povo, na data de 26/03/2017, na editoria de Moda e Beleza, de Mori (2017), afirma que nolugar de apenas disfarçar as linhas de expressão, o botox é capaz de prevenir o surgimento das rugas ao longo do tempo. O conteúdo do texto traz que:

o sonho de toda mulher em ter uma pele saudável, tonificada e livre de rugas não é nenhum segredo. A novidade da vez, porém, envolve o botox, um aliado dos procedimentos estéticos e velho conhecido de todos. Em vez de apenas disfarçar as linhas de expressão, ele é capaz deprevenir seu surgimento ao longo do tempo. 
Percebe-se na narrativa que o medo do corpo envelhecer é algo genérico e que existem maneiras do sujeito retardar esse processo natural, como as rugas. E o botox é uma das soluções. Segundo LE BRETON (2001, p. 243):

as sociedades ocidentais, confrontadas à dessimbolização de sua relação com o mundo, onde as relações formais vencem sempre mais as relações de sentido (e, portanto, de valores), engedram formas inéditas de socialização que privilegiam o corpo, mas o corpo enluvado de sinais efêmeros, objeto de um investimento crescente.

Um imaginário do corpo como parceiro, não envelhecido, com a melhor apresentação possível, ao ostentar sinais eficazes da juventude, mesmo com o passar do tempo. Um representante do que o sujeito é e do que o julgam (LE BRETON, 2011).

Na unidade comunicativa 6, do blog Palpite de Alice, com o título, “Diário de uma triatleta - Quando o esporte desafia a beleza!", autoria de Duarte (2017), publicada no jornal Gazeta do Povo (online) em 22 de fevereiro de 2017, alerta para o fato de que há a necessidade de tratamentos para a pele quando o sujeito de expõe ao sol em seus exercícios físicos, com o objetivo de prevenir o envelhecimento. A autora argumenta:

se você não sofre com manchas provenientes da exposição ao sol e da liberação excessiva de radicais livres pelo organismo através de atividade física de alta intensidade, saiba que de qualquer maneira, você pode e deve fazer um tratamento preventivo contra o envelhecimento da pele (DUARTE, 2017).

Assim o texto traz códigos do saber viver. As regras, os marcos necessários para que o sujeito se sinta em harmonia com o seu corpo, com o outro e com o seu imaginário. Um corpo que se apresenta como uma medida na qual são avaliadas, por todos os atores sociais, se as ações foram cumpridas ou se deixaram de ser feitas. Uma medida do corpo com o mundo. O corpo como "a interface entre o social e o individual, a natureza e a cultura, o psicológico e o simbólico" (LE BRETON, 2003, p. 97).

A unidade 7, com o título, "Crise freia investimento em inovação no Brasil”, de Junges (2017), publicada em 03 de fevereiro de 2017, afirma que o envelhecimento da população pode custar caro no futuro do 
país. Um país de pessoas idosas, mesmo antes de se tornar uma nação desenvolvida. "Estudos indicam, contudo, que os países tendem a ficar menos inovadores à medida que sua população envelhece - e o Brasil está passando por uma transição demográfica mais rápida entre os emergentes"(JUNGES, 2017, p.1). Percebe-se que o texto pode trazer a representação de um idoso não criativo, não inovador e sem lugar no ambiente de trabalho. Um culto ao não envelhecimento, um envelhecimento intolerável, inclusive no mercado de trabalho.

Na unidade 8, com o título, "Tecnologia pode tornar imortal quem hoje tem menos de 40 anos", do Estadão (2017), publicada na Gazeta do Povo (online) em 02 de fevereiro de 2017, contém diversos contextos que podem ser significados dentro da negação do envelhecimento, inclusive sua chamada inicial. Um apelo ao imaginário do corpo como máquina. Afirma o conteúdo:

o pesquisador britânico Aubrey de Grey falou sobre como a tecnologia pode ser usada para tratar doenças e parar o envelhecimento. Em apresentação que se seguiu à de Karen, no palco principal da Campus, ele fez uma proposição ousada. "Qualquer ser humano que tem menos de 40 anos hoje poderá ver o desenvolvimento de tecnologias que vão lhe permitir se tornar imortal" (ESTADÃO CONTEÚDO, 2017, p.1).

Parar o envelhecimento é algo que a tecnologia promete, segundo a pesquisa apresentada na notícia. Paradigma do corpo máquina no qual a tecnologia corrobora na manutenção e troca de peças como se fosse um relógio. Uma máquina que precisa ser cuidada - "devemos merecer nossa juventude, sua forma, seu look” (LE BRETON, 2011, p.245).

A unidade comunicativa 9, com o título, Maratonista de 85 anos é tão rápido que espanta até cientistas, do The New York Times, publicada na Gazeta do Povo (online) no dia 20 de janeiro de 2017, contém contextos que englobam códigos do saber viver, como a forma física, o treino físico, a superação de realizar uma maratona mesmo aos 85 anos e ao causar admiração em cientistas e médicos. Afirma o texto: "tendo estabelecido dezenas de recordes de sua faixa etária em maratonas, Whitlock permanece na vanguarda dos atletas idosos que levaram os cientistas a reavaliar as possibilidades de envelhecimento e desempenho". O conteúdo pode levantar representações do culto ao não envelhecimento pela continuação de uma forma física semelhante a de um jovem. LE BRETON (2011, p. 260) embasa esta percepção do consumo ao não envelhecimento: 
o mergulho no universo interior em busca de sensações insólitas, a partida patrocinada nos desertos ou nos gels, o gosto do confronto com os elementos nos limites de si mesmo, as provas de maratona, ou de esqui nórdico realizada por seu termo malgrado a fadiga, o jogging cotidiano ou as horas semanais vividas nos ginásios para manter a forma, estas são práticas e discursos que se fazem sob o controle difuso de uma gama de valores ao mesmo tempo comumente e diferencialmente partilhados pelos grupos sociais: a juventude, a forma, a saúde, a educação, a sedução, a resistência, a flexibilidade... valores cardinais da publicidade. Esses mitologias modernas valorizam qualidades ligadas à condição física.

A unidade comunicativa 10, com o título, "Ácidos para a pele podem ser usados no verão", publicada na Gazeta do Povo (online) no dia 18 de janeiro de 2017, assinada pela Redação do jornal, traz a questão da utilização de cosméticos / ácidos para prevenir o envelhecimento. Ao abordar a questão do ácido hialurônico, o texto afirma: "o envelhecimento diminui o ácido, o que afeta também a hidratação e a elasticidade da pele. Por isso, é muito usado na hidratação, em fórmulas anti-idade". A palavra anti-idade e todas as suas siginificações no culto ao não envelhecimento a partir de uma visão instrumental do corpo.

Da dietética aos cosméticos, das academias de musculação às maratonas, do cuidado com o seu visual ao funcionamento perfeito de sua máquina,são fortalecidos imaginários do corpo por meio do envelhecimento intolerável, da responsabilidade do sujeito frente à velhice e da luta pela manutenção incessante de um corpo jovem.

\section{Considerações finais}

Este artigo teve como objetivo demonstrar, por meio de um recorte midiático, narrativas de representações sociais que cultuam o não envelhecimento dos sujeitos. Um imaginário do corpo que se baseia na manutenção da juventude física e emocional.

O envelhecimento é um processo heterogêneo, como toda fase da vida, e se vincula aos aspectos sociais, históricos e econômicos decada sujeito. E, é justamente pela heterogeneidade, pelas múltiplas vozes sociais, que se formam as representações do envelhecimento, que, por sua vez, alimentam, incessantemente, o imaginário do corpo e da velhice. No entanto, o que se levanta é que os códigos do saber viver, e as regras para combater a velhice, são fortalecidos midiaticamente a todos, 
podendo causar uma negação ao processo de envelhecer, assim como a construção de julgamentos sociais estigmatizados.

Diante as unidades comunicativas estudadas, verifica-se, entre os resultados, a enaltação midiática de valores simbólicos como juventude, vitalidade e corpo físico perfeito. Paradigmas do imaginário do corpo que podem dificuldar as vivências no processo do envelhecimento. Portanto, o maior dos prejuízos causado pela mídia está nas narrativas de serviços ou produtos (consumo cultural) que prometem verdadeiros milagres, em prol da eterna juventude. Como afirma Junges (2004), é louvável e promissora a melhoria quantitativa e qualitativa da vida dos idosos, mas essa representação do sonho da imortalidade física dificulta a vivência do processo do envelhecimento, pela falta da integração sadia entre esse processo e os idosos.

Importante salientar que este estudo teve como objetivo estudar narrativas da mídia que trazem o imaginário do não envelhecer como regra e cobrança social. Não houve pretensão de discutir fisiologicamente os conteúdos abordados, apenas demonstrar a série de rituais e códigos do saber viver que os sujeitos têm com seus corpos na modernidade.

Acredita-se também em uma tendência no fortalecimento de narrativas midiáticasda responsabilidade do sujeito frente ao envelhecimento, pois os avanços tecnológicos e descobertas científicas, que permeiam a manutenção do corpo físico,devem enaltecer ainda mais o imaginário do corpo perfeito. É preciso, assim, continuar a refletir sobre a responsabilidade social midiática para que uma velhice positivada seja possívelem uma sociedade que cultua a juventude e "não sabe mais simbolizar o fato de envelhecer ou de morrer” (LE BRETON, 2011, p.224).

\section{REFERÊNCIAS}

AGÊNCIA DO ESTADO. Um terço dos casos de demência pode ser evitada com 9 mudanças de hábitos. Jornal Gazeta do Povo (online), Curitiba, PR, 20 de julho de 2017. Disponível em: http://www.gazetadopovo.com.br/viver-bem/saude-e-bem-estar/ como-prevenir-a-demencia-e-o-alzheimer/. Acesso em 30 jul. de 2017.

CASTRO, Ana Lúcia de. Corpo, consumo e mídia. Comunicação, mídia e consumo. São Paulo, SP: ESPM, vol. 1, n.1, Mar. 2004. Disponível em: http://revistacmc. espm.br/index.php/revistacmc/article/view/2. Acesso em 01 jul. 2017.

DA REDAÇÃO. Ácidos para a pele podem ser usados no verão. Jornal Gazeta do Povo (online), Curitiba, PR, 18 de janeiro de 2017. Disponível em: http://www. 
gazetadopovo.com.br/viver-bem/saude-e-bem-estar/saude/acidos-para-a-pelepodem-ser-usados-no-verao-veja-quais/. Acesso em 05 mai. 2017.

DEBERT, Guita. A reinvenção da velhice. São Paulo: Edusp, 1999.

DUARTE, Cyntia. Diário de uma triatleta - Quando o esporte desafia a beleza! Jornal Gazeta do Povo (online), Curitiba, PR, 2 de fevereiro de 2017. Disponível em: http:// www.gazetadopovo.com.br/blogs/palpite-de-alice/diario-de-uma-triatleta-quando-oesporte-desafia-beleza/. Acesso em 05 de maio de 2017.

ESTADÃO CONTEÚDO. Tecnologia pode tornar imortal quem hoje tem menos de 40 anos, defende pesquisador. Jornal Gazeta do Povo (online), Curitiba, PR, 2 de fevereiro de 2017. Disponível em: http://www.gazetadopovo.com.br/economia/ inteligencia-artificial/tecnologia-pode-tornar-imortal-quem-hoje-tem-menos-de-40anos-defende-pesquisador-31y717kgtpq7zk03zmzwn95ng. Acesso em 05 mai. 2017.

GAZETA DO POVO. Jornal Gazeta do Povo (online). Disponível em: http:// gazetadopovo.com.br. Acesso em 30 jul. 2017.

IBGE - Instituto Brasileiro de Geografia e Estatística. Brasil: uma visão geográfica e ambiental no início do século XXI. Disponível em: http://biblioteca.ibge.gov.br/ biblioteca-catalogo?id=297884\&view=detalhes. Acesso em 15 dez. 2016.

JUNGES, Cíntia. Crise freia investimento em inovação no Brasil. E isso pode custar caro no futuro. Cada vez mais, país corre o risco de envelhecer antes de se tornar uma nação desenvolvida. Jornal Gazeta do Povo (online), Curitiba, PR, 03 de fevereiro de 2017. Disponível em: http://www.gazetadopovo.com.br/economia/ crise-freia-investimento-em-inovacao-no-brasil-e-isso-pode-custar-caro-no-futurocfmqem1gubpli0ridgmxo7t98. Acesso em 05 mai. 2017.

JUNGES, José Roque. Uma Leitura crítica da situação do idoso no atual contexto sociocultural. Revista: Estudos Interdisciplinares do Envelhecimento. Porto Alegre, RS: vol.6, 2004. Disponível em: http://seer.ufrgs.br/index.php/RevEnvelhecer/ article/viewFile/4747/2667. Acesso em 10 jun. 2017.

LE, BRETON, David. Antropologia do Corpo e Modernidade. Petrópolis, RJ: Vozes, 2011.

.Adeus ao corpo: antropologia e sociedade. Campinas:

Papirus, 2003

LEMES, Maria Carolina. 10 motivos para praticar Pilates na melhor idade. Jornal Gazeta do Povo (online), Curitiba, PR, 08 de abril de 2017..http://www.gazetadopovo. com.br/blogs/palpite-de-alice/10-motivos-para-praticar-pilates-na-melhor-idade/. Acesso em 30 jul. 2017.

MARQUES, Sibila. Discriminação da terceira idade. Lisboa: FFMS, 2011. 
MATOS, Helena. Capital social e comunicação. Interfaces e articulações. São Paulo: Summus, 2009.

MILLÉO, Amanda. Adultos e idosos não devem parar de tomar leite, diz Dráuzio Varella. Jornal Gazeta do Povo (online), Curitiba, PR, 08 de abril de 2017. Disponível em: http://www.gazetadopovo.com.br/viver-bem/saude-e-bem-estar/adultos-naodevem-parar-de-tomar-leite-diz-drauzio-varella/. Acesso em 20 jun. 2017.

MORI, Marina. "Botox pode, sim, prevenir rugas", afirmam especialistas. Jornal Gazeta do Povo (online), Curitiba, PR, 26 de março de 2017. Disponível em: http:// www.gazetadopovo.com.br/viver-bem/moda-e-beleza/botox-pode-sim-prevenir-rugasafirmam-especialistas/. Acesso em 15 jun. 2017.

SILVERSTONE, Roger. Por que estudar a mídia? São Paulo, SP: Edições Loyola, 2002.

STACHESKI, Denise Regina. Comunicação Pública: Idosos e Representações Sociais (ebook). Florianópolis, SC: Combook, 2014.

THE NEW YORK TIMES. Aprender a dançar o minueto ou o fandango protege nosso cérebro do envelhecimento? Jornal Gazeta do Povo (online), Curitiba, PR, 09 de abril de 2017. Disponível em: http://www.gazetadopovo.com.br/saude/aprendera-dancar-o-minueto-ou-o-fandango-protege-nosso-cerebro-do-envelhecimentob2abvi47lcwtmsigdiw542eck. Acesso em 30 jul. 2017. . Maratonista de 85 anos é tão rápido que espanta até cientistas britânico. Jornal Gazeta do Povo (online), Curitiba, PR, 20 de janeiro de 2017. Disponível em: http://www.gazetadopovo.com.br/esportes/ poliesportiva/maratonista-de-85-anos-e-tao-rapido-que-espanta-ate-cientistas656vrjhlotuupw7y080dnsmyj. Acesso em 05 mai. 2017.

VIEIRA, Teresa.; NASCENTES, Claudilene. O idoso, a publicidade e o direito do consumidor, 2002. Disponível em: https://jus.com.br/artigos/4621/o-idoso-apublicidade-e-o-direito-do-consumidor. Acesso em 01 jul. 2017. 